\title{
Experimental fluid mechanics of an Ediacaran frond
}

\author{
Amy Singer, Roy Plotnick, and Marc Laflamme
}

\begin{abstract}
Ediacaran fronds are iconic members of the soft-bodied Ediacara biota, characterized by disparate morphologies and wide stratigraphic and environmental ranges. As is the case with nearly all Ediacaran forms, views of their phylogenetic position and ecology are equally diverse, with most frond species considered as sharing a similar ecological guild rather than life history. Experimental biomechanics can potentially constrain these interpretations and suggest new approaches to understanding frond life habits.

We examined the behavior in flow of two well-know species of Charniodiscus from the Mistaken Point Formation of Newfoundland, Canada (Avalon assemblage): Charniodiscus spinosus and C. procerus. Models reflecting alternative interpretations of surface morphology and structural rigidity were subjected to qualitative and quantitative studies of flow behavior in a recirculating flow tank.

At the same velocities and orientations, model C. procerus and $C$. spinosus experienced similar drag forces; the drag coefficient of $C$. procerus was smaller, but it is taller and thus experiences higher ambient flow velocities. Reorientation to become parallel to flow dramatically reduces drag in both forms. Models further demonstrated that $C$. procerus (and to a lesser extent $C$. spinosus) behaved as self exciting oscillators, which would have increased gas exchange rates at the surface of the fronds and is consistent with an osmotrophic life habit.
\end{abstract}

Amy Singer. Geosciences Department, The University of Montana, 32 Campus Drive \#1296, Missoula, MT 59812-1296; amy.singer@umontana.edu

Roy Plotnick (correspondence author). Department of Earth and Environmental Sciences, University of Illinois at Chicago, 845 W. Taylor St., Chicago, IL 60607; plotnick@uic.edu

Marc Laflamme. Department of Paleobiology, Smithsonian Institution, PO Box 37012, MRC 121, Washington, DC 20013-7012; LaflammeM@si.edu

Keywords: Ediacaran, biomechanics, functional morphology 

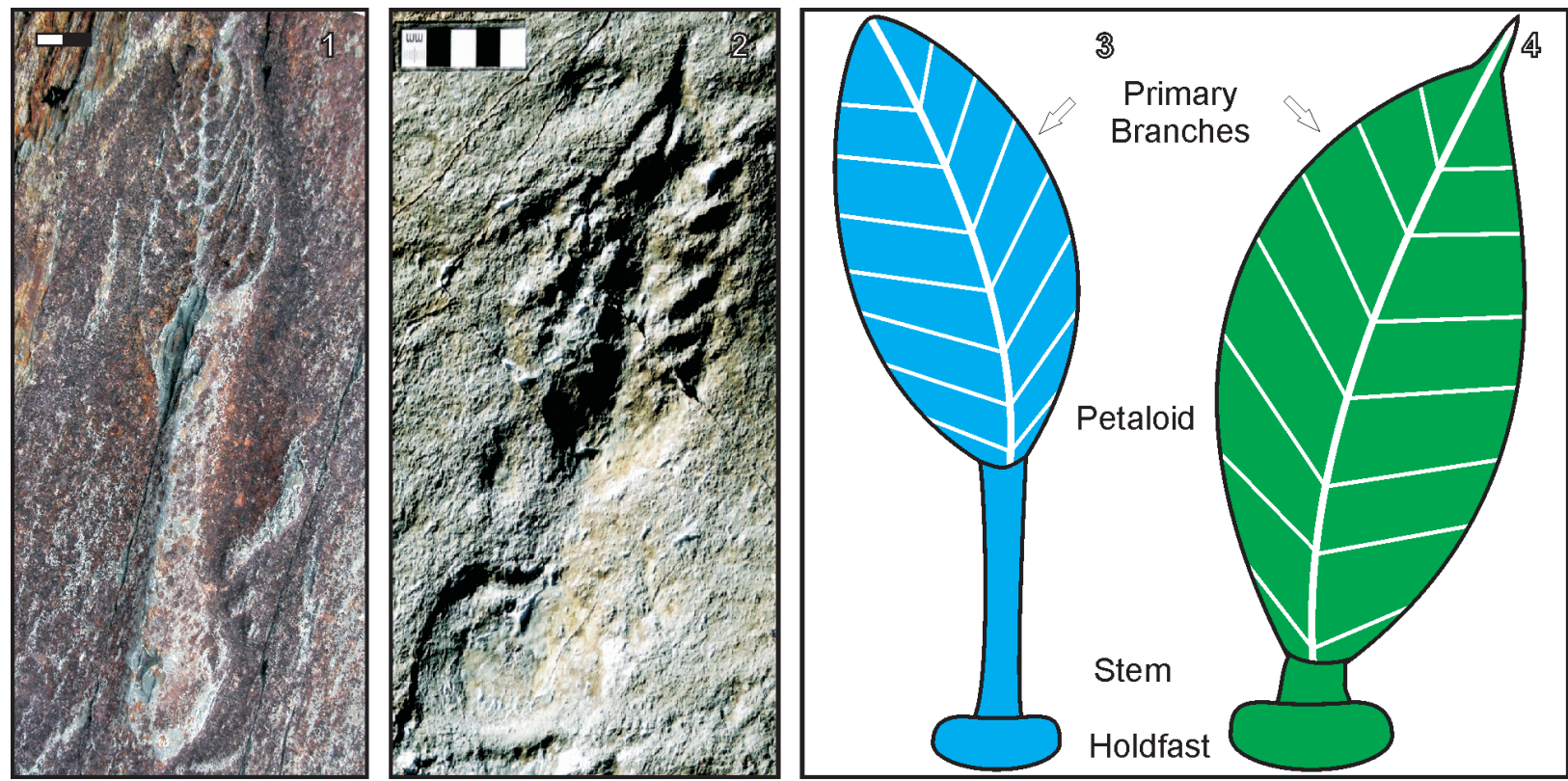

FIGURE 1. Charniodiscus from the Mistaken Point Formation: (1) Field photograph of Charniodiscus procerus with a prominent stem. (2) Field photograph of $C$. spinosus with a distal spine and shorter, poorly-preserved stem. Scale bar increments equal $1 \mathrm{~cm}$. Labeled cartoon reconstructions of (3) Charniodiscus procerus and (4) Charniodiscus spinosus. Note presence of spire extending beyond frond in latter form.

\section{INTRODUCTION}

Despite intensive work over the past half-century, the diverse fossils that comprise the Ediacara biota remain both phylogenetically and ecologically enigmatic. They have been interpreted as several distinct members of crown-group Metazoa (Gehling, 1991; Dzik, 2003; Waggoner, 2003) or even as an unrelated extinct form of unicellular/ multicellular life, the Vendobionta (Seilacher, 1989, 1992; Buss and Seilacher, 1994). In a recent review, Xiao and Laflamme (2009) reject both end members of these positions and suggest that in addition to possible stem-group bilaterians and metazoans, they encompass algae, protists, fungi, microbial colonies, and even extinct higher-order clades which lie outside of Metazoa. As such, the Ediacara biota represents a temporally restricted yet phylogenetically diverse assemblage of organisms all sharing a relatively similar mode of preservation (Narbonne, 2005).

These same uncertainties apply to the polyphyletic Ediacaran fronds, such as Rangea, Charnia, and Charniodiscus. Fronds have the greatest geographic and ecological range of all the Ediacaran organisms. They are dominant in the oldest assemblages and persist through the end of the Neoproterozoic (Peterson et al., 2005; Laflamme and Narbonne, 2008a, 2008b). Their distribution is further extended if discoid genera such as Aspi- della are interpreted as holdfasts where the fronds have been detached (Gehling et al., 2005) or not preserved (Laflamme et al., 2011). Early workers believed the fronds to be impressions of photoautotrophic alga (Ford, 1958), but their occurrence in localities reconstructed as being below the photic zone rules out phototrophism (Wood et al., 2003; Narbonne, 2005). As such, Ediacaran fronds are most widely interpreted to have either captured particles as filter feeders or absorbed nutrients directly from the water column (Clapham and Narbonne, 2002; Laflamme et al., 2004, 2009).

A number of modern and fossil organisms have exploited the frond morphospace; plants, animals, and protists all build fronds (Raven et al., 2005; Laflamme and Narbonne, 2008a, 2008b). Correspondingly, Ediacaran fronds have been variously assigned to Cnidaria, lichens, fungi (all of which contain frond-like forms), and to the extinct kingdom Vendobionta (Seilacher, 1989). Laflamme and Narbonne (2008a) further suggest that, based on differences in branching and detailed surface morphology, the traditional grouping of all fronds into a single group based on overall gross morphology is invalid, and more likely represent a shared ecology, not ancestry.

In this paper, we describe the results of experiments on the fluid mechanics of two Ediacaran frond species, Charniodiscus spinosus and C. pro- 
cerus (Laflamme et al., 2004). These species were specifically chosen due to their detailed descriptions and exhibition of two unique morphotypes: $C$. spinosus with a large, broad frond petaloid and $C$. procerus with a relatively smaller petaloid but markedly longer stem (Figure 1). Physical models were used to examine the forces these fronds experienced and to visualize flow patterns around them. Alternate reconstructions were tested to evaluate the effects of different morphologic interpretations on the interaction of these organisms with flow. Our intent is to constrain potential interpretations of the ecology of some of the best known Ediacaran fronds, which should have direct implications for most if not all of them.

\section{Morphology of Charniodiscus}

The anatomy of Ediacaran fronds was described in Laflamme et al. (2004) and Laflamme and Narbonne (2008a). In the literature, the term "frond" has been applied both to the entire structure as well as the leaf-shaped blade or petalodium (Figure 1). The stalk refers to the central axis within the petaloid(s), while the stem links the stalk and petaloids to the rooting holdfast. This paper follows Laflamme and Narbonne's (2008a) nomenclature where "frond" refers to the entire structure from holdfast to tip, and petalodium refers to the blades extending from the stem. The organism was attached to the seafloor by means of a holdfast, which may have adhered to a biomat or been embedded in the sediment/microbial mat (Laflamme et al., 2004; Laflamme and Narbonne, 2008a; Tarhan et al., 2010; Laflamme et al., 2011). The holdfast may have also incorporated sand grains to provide additional stability (Laflamme et al., 2011).

The morphology and morphometrics of $C$. spinosus and $C$. procerus from the Avalon Zone of Newfoundland were reported by Laflamme et al. (2004). Both species are interpreted by Laflamme and Narbonne (2008a) as having branches that are anchored to a central stalk and extend to the margins of the petalodium, and which are interconnected by a solid membrane (Figure 1). These branches may in turn have second and third order branching (Arborea-type branching of Laflamme and Narbonne, 2008a; although see Brasier and Antcliffe, 2009). This contrasts with modern sea pens, in which the branches are free, allowing flow between them (Seilacher, 1989). Unfortunately, the mode of fossilization does not preserve finer structures that may or may not have been present on the surface of the petalodium (Laflamme and Narbonne 2008a).

The petalodium of $C$. procerus is lanceolate and represents on average approximately $50 \%$ of the total length of the organism $(n=13$; Laflamme et al., 2004). The stem is quite prominent averaging $35 \%$ of the total length, and where it connects to the petaloid, a distinct bend of up to $37^{\circ}$ can be measured in specimens at Mistaken Point. Charniodiscus procerus also has the relatively smaller basal holdfast when compared to C. spinosus.

C. spinosus has an ovate petalodium with a stalk that extends beyond the tip of the frond forming a spire and comprises about $61 \%$ of the total length ( $n=27$; Laflamme et al., 2004). The stem is shorter than that in C. procerus (13\% of the length) and lacks a bend.

The preservation of Ediacaran fossils, even at the exceptional Mistaken Point locality, obscures fine details that may have been present, allowing for a number of different reconstructions of surface morphology to be proposed. The classic interpretations of Ediacaran fronds as stem group members of Cnidaria reconstructs them with free branches resembling modern Pennatulacea (Glaessner,1984; Gehling,1991). Seilacher (1992) favored a quilted body plan not unlike an air mattress. Our preferred interpretation is of a solid frond with a thin membrane between primary branches, and second or third order branching which may or may not be free from the membrane.

\section{Experimental Fluid Mechanics of Charniodiscus}

With the notable exception of Schopf and Baumiller (1998), little has been done to physically test proposed morphologies and life habits of Ediacaran organisms. Our study addressed the following issues:

What is the effect of frond stiffness on its behavior in flow? Frond stiffness determines if interactions with flow would change its shape or orientation. A range of body densities and compliances have been proposed for the Ediacara biota, with mechanical properties similar to jellyfish being most often suggested (Seilacher 1989; Schopf and Baumiller, 1998). Taphonomic evidence reveals that at least some parts of the organism were soft enough to be deformed by burial yet rigid enough to resist complete collapse (Retallack, 1994; Seilacher, 1999; Laflamme et al., 2004, 2011; Gehling et al., 2005), although these parameters could reflect intricacies associated with the "death mask" 
TABLE 1. Dimensions of models used in this study.

\begin{tabular}{lccccc}
\hline & $\begin{array}{c}\text { Frond length } \\
(\mathbf{m})\end{array}$ & $\begin{array}{c}\text { Frond width } \\
(\mathbf{m})\end{array}$ & $\begin{array}{c}\text { Stem length } \\
(\mathbf{m})\end{array}$ & $\begin{array}{c}\text { Spire length } \\
(\mathbf{m m})\end{array}$ & $\begin{array}{c}\text { Frontal surface } \\
\text { area }\left(\mathbf{m}^{\mathbf{2}}\right)\end{array}$ \\
\hline C. procerus & 0.096 & 0.046 & 0.060 & 0 & 0.00419 \\
C. spinosus & 0.010 & 0.056 & 0.020 & 0.018 & 0.00472 \\
\hline
\end{tabular}

preservation and thus have little to do with original tissue rigidity and lability (Gehling, 1999; Darroch et al., 2012). It has also been proposed that hydrostatic pressure or internal gel allowed the frond to be elevated into the water column, and resulted in the frond behaving somewhat rigidly in fluid flow (Seilacher, 1992; Tarhan et al., 2010).

How does orientation with respect to flow change drag and flow patterns? Drag is the hydrodynamic force that pushes a body downstream and may damage fine structures or uproot organisms (Levinton, 2001). However, organisms may also make use of drag to facilitate feeding, respiration, and reproduction (Vogel, 1981). An understanding of drag forces experienced by Ediacaran fronds can lend insight into possible life modes. Taphonomic evidence suggests that some fronds were oriented near parallel to the substrate and were thus parallel to flow (Laflamme et al., 2007; Seilacher, 1999). Tarhan et al. (2010) illustrated them as being deformed by unidirectional currents to become parallel to the substrate. This orientation can also be seen in highly compliant modern organisms, such as marine algae and some gorgonians, as a mechanism of drag reduction or feeding enhancement (Sponaugle and Labarbera, 1991; Gaylord et al., 2001; Denny and Gaylord, 2002). On the other hand, most erect filter feeders are usually close to perpendicular to ambient flow (Wainwright and Dillon, 1969; Baumiller, 1990; Riisgard and Larsen, 2010). Particle capture suspension feeders such as soft and stony corals tend to prefer orientations of $60^{\circ}$ to $90^{\circ}$ so that polyps can feed in the turbulent wake downstream of the colony (Wainwright and Dillon, 1969; Vogel, 1981).

What is the effect of frond three-dimensional morphology on flow interaction and forces? Although there is significant disagreement on details, all reconstructions of Ediacaran fronds incorporate significant three-dimensional morphology. In modern macroalgae, three-dimensional morphology has a strong effect on flow behavior (Koehl and Alberte, 1988; Koehl et al., 2008). In high flow environments, macroalgal blades are narrow and flat and flutter slowly; this reduces drag.
The same species in low velocity flow have wider and thinner blades with ruffled edges and flutter rapidly; these forms have higher drag at the same velocities. Koehl and Alberte (1988) found that blade movement, by stirring water near the surface, enhances rates of uptake (cf. Hurd and Pilditch, 2011).

What is the significance of the morphologic differences between the two species of Charniodiscus? In particular, what is the potential significance of the bend in $C$. procerus?

What is the possible range of forces exerted on the holdfast? It has been suggested that drag on fronds led to their being dragged through the biomat, producing the distinctive "mop" form (Tarhan et al., 2010). Alternatively, isolated discoid forms, such as Aspidella, have been suggested to be the remnants of frond holdfasts, perhaps where the remainder of the organism has been torn loose (Gehling et al., 2000). An estimate of the drag forces acting on the fronds lead the way to examining these scenarios.

\section{MATERIALS AND METHODS}

\section{Frond Models}

Physical models were constructed using corrected mean values for overall frond morphology of C. spinosus and $C$. procerus according to Laflamme et al. (2004) (Table 1; Figure 2). The Avalon Zone has undergone tectonic deformation causing about $40 \%$ shortening of the fossils, which was corrected by Laflamme et al. (2004) using the mathematical and photographic techniques of Wood et al. (2003). Because of the nature of preservation, thickness is unknown, but has been proposed to range from of $0.001-0.010 \mathrm{~m}$. For this study, thickness was standardized to $0.008 \mathrm{~m}$ for all models.

Multiple models for both species were made with the same dimensions but with differing surface textures. Four surface reconstructions were tested (Figure 3). Smooth models (Figure 3.1) had no surface texture. Quilted models (Figure 3.2) were based on the reconstruction of Charnia by Seilacher (1992). Membrane models (Figure 3.3) rep- 


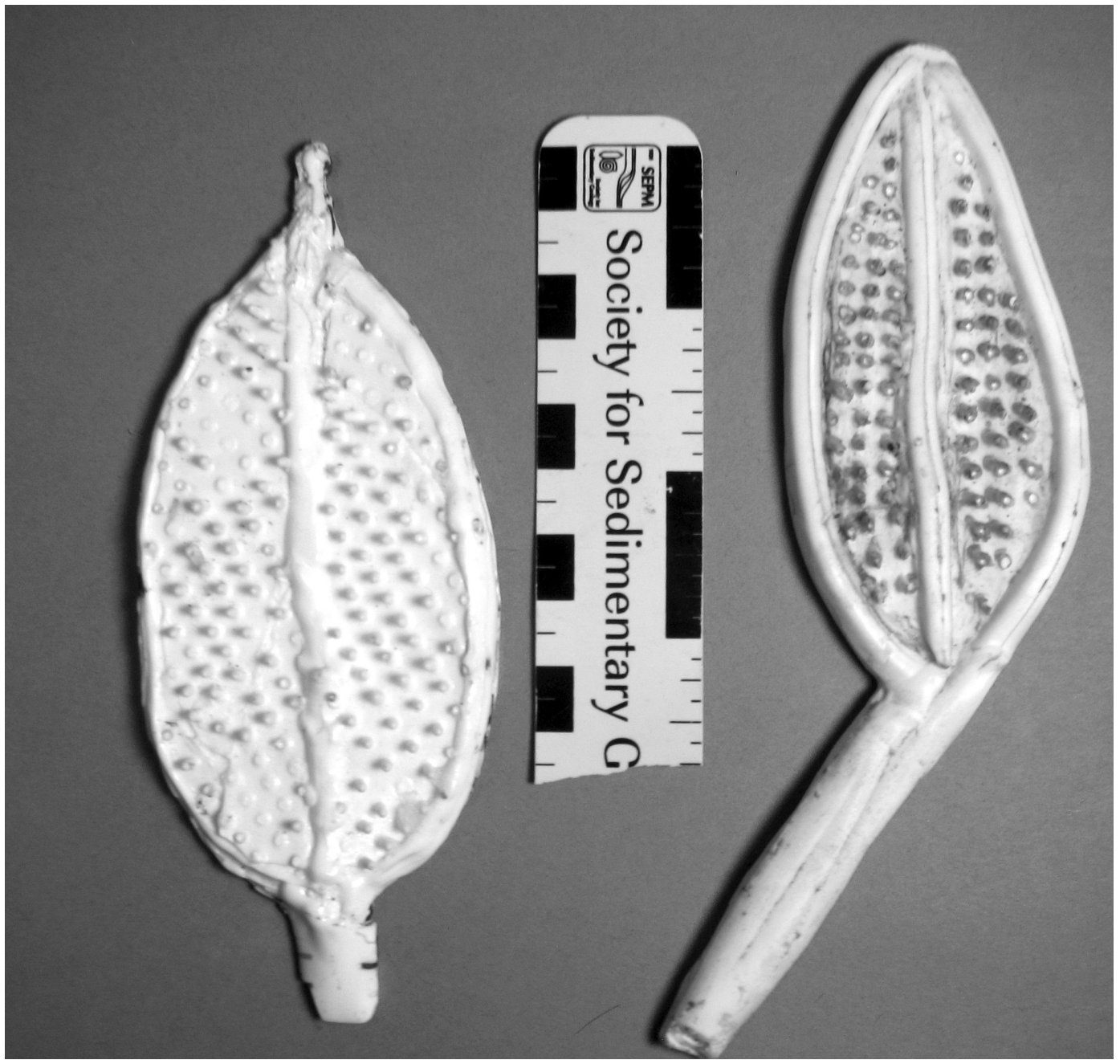

FIGURE 2. Epoxy models of Charniodiscus spinosus and C. procerus.

resented two orders of branching with an interconnecting membrane. The final model type, Three- $D$, added a tertiary order of branching extending perpendicular from the surface (Figure 3.4).

For each of the species and surface texture combinations (total of eight), three sets of models were cast to simulate a range of compliances from rigid to very flexible. Rigid models were cast in a two part epoxy. Semi-compliant models were made using silicone rubber. Lastly, flexible models were cast in a carrageenan/agar mix.

\section{Flow Modeling}

All trials were run in a unidirectional recirculating flow tank (Vogel and LaBarbara, 1978; Baumiller and Plotnick, 1989). The working area of the flow tank measures $0.24 \times 0.24 \times 1.20 \mathrm{~m}$, with a sediment trough filled with medium grained sand. The tank's maximum sustainable velocity is $0.20 \mathrm{~m} / \mathrm{s}$, which is in the range of velocities for currents interpreted for the Mistaken Point locality and found in the modern deep-sea (Wood et al., 2003; Rhein, 1994). Flow velocities for each run were determined by timing the movement of a dye plume.

Frond models were initially positioned such that the major axis of the petaloid was oriented at angles of $0^{\circ}-90^{\circ}$ from the horizontal and the minor axis was perpendicular to flow, so that the widest surface (frontal area) always faced into the flow direction (Figure 4). The models made of compliant materials were allowed to reorient in the flow; all of these ended up being more or less parallel to the flow direction.

To quantify drag exerted on the fronds, downstream deflection forces were measured with strain gauges mounted on a stiff metal plate (Plotnick and Baumiller, 1987). Models were attached to a metal rod (sting) mounted on the plate using hot glue. Downstream bending of the strain plate produced 


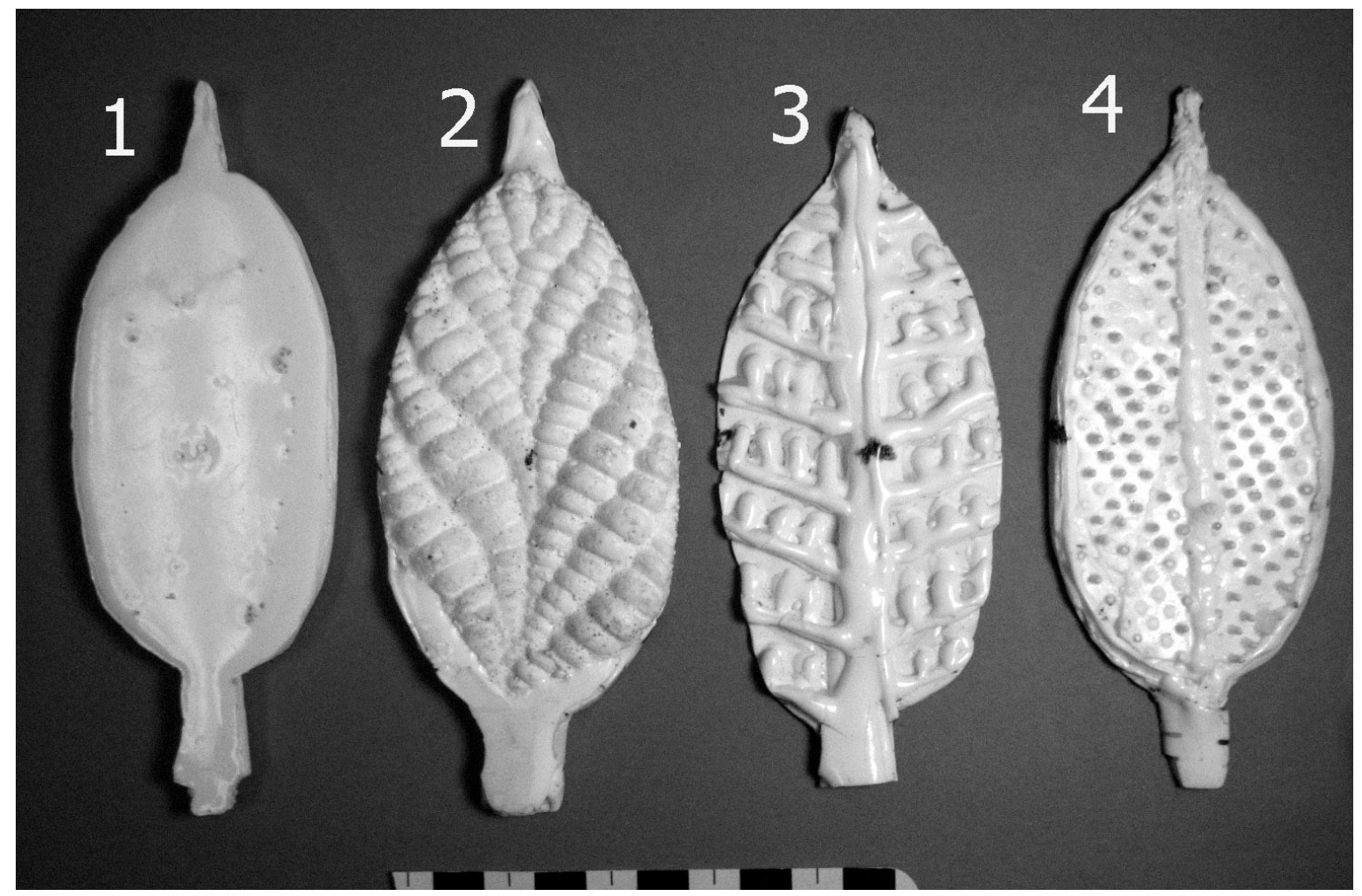

FIGURE 3. Reconstructions of Charniodiscus spinosus and the surface textures tested. (1) smooth model with no interpreted structure, (2) quilted model based on reconstruction of Charnia quilts by Seilacher(1992), (3) membrane model with two orders of branching connected by a membrane, and (4) 3D with perpendicular rods to represent three orders of branching with a membrane. The same textures were evaluated in C. procerus as well. Scale bar equals $1 \mathrm{~cm}$ increments.

changes in resistance in the strain gauges that were measured in $\mathrm{mV}$ with a digital multimeter. These readouts were converted to force in Newtons by hanging analytical weights vertically from the end of the sting. For determination of relative drag coefficients, the centers of the frontal area of the model fronds were placed in the middle of the flow (Figure 4). For comparison of drag force on the base of the stem, the base was placed as close as possible to the bottom of the tank.

The drag on an object varies in a complex way with shape, orientation, and the Reynolds number, which in turn is a function of the size of the object and the viscosity and velocity of the fluid (Vogel, 1981, 2003). Comparing drag among different objects or the same object under different conditions can best be done by converting drag into the dimensionless drag coefficient $C_{d}$ :

$$
C_{d}=\frac{2 D}{u^{2} A_{p r} \rho}
$$

where $D$ is the measured drag force in Newtons, $u$ is the water velocity, $A_{p r}$ is the frontal surface area of the frond (Table 1), and $\rho$ is the density of water (we used the density value of tap water at $17^{\circ} \mathrm{C}=998.8 \mathrm{~kg} / \mathrm{m}^{3}$ ). Objects of the same shape and size have the same drag coefficients at the same Reynolds number. For many objects, $C_{d}$ is similar over a wide range of Reynolds numbers.

It should be pointed out that because the values of $C_{d}$ are dependent on the velocity squared, small errors in velocity determination can produce large deviations in the calculated values of the drag coefficient. As a result, multiple velocity calibrations were done before and after each experimental run. Runs for comparison of drag coefficients were performed at average velocities $u$ of $0.095 \mathrm{~m} / \mathrm{s}$.

Flow patterns were observed using fluorescein dye injected into flow over time with syringes and catheter tubing to create streaklines. Transitions from laminar to turbulent flows, vortices and eddies, and boundary layer thickness were noted. 


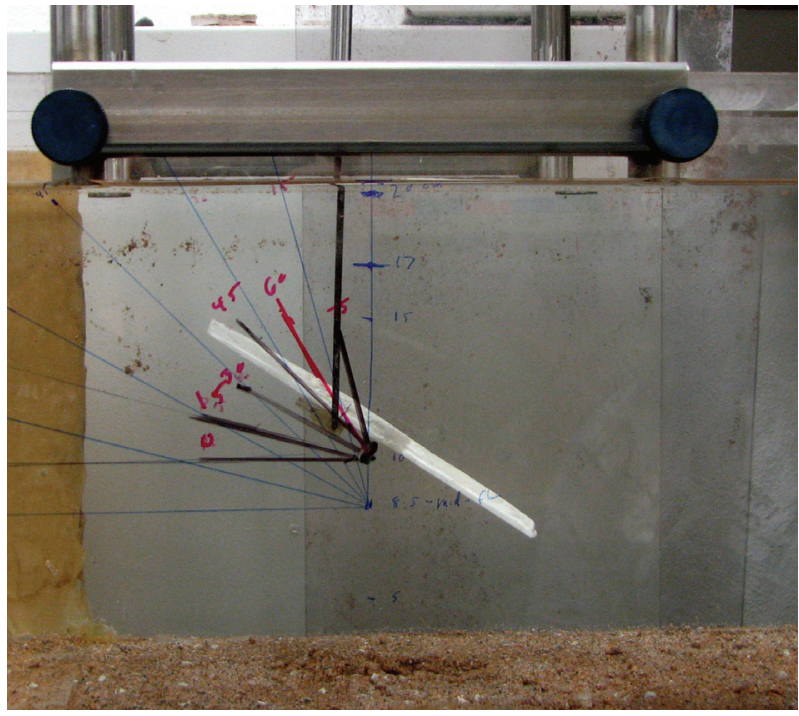

FIGURE 4. Charniodiscus spinosus model oriented for determination of drag coefficients. Flow is from right to left.

Streaklines were also observed to determine if surface textures entrained flow along branches and canals. Most visualizations were carried out at 0.02 $\mathrm{m} / \mathrm{s}$ to facilitate ease in observation of dye movements. Additional qualitative observations were carried out at $0.10 \mathrm{~m} / \mathrm{s}$ in order to document compliant model flow induced movements. Flow patterns and movements were recorded with a Canon PowerShot S3 IS digital camera, using both still and video modes.

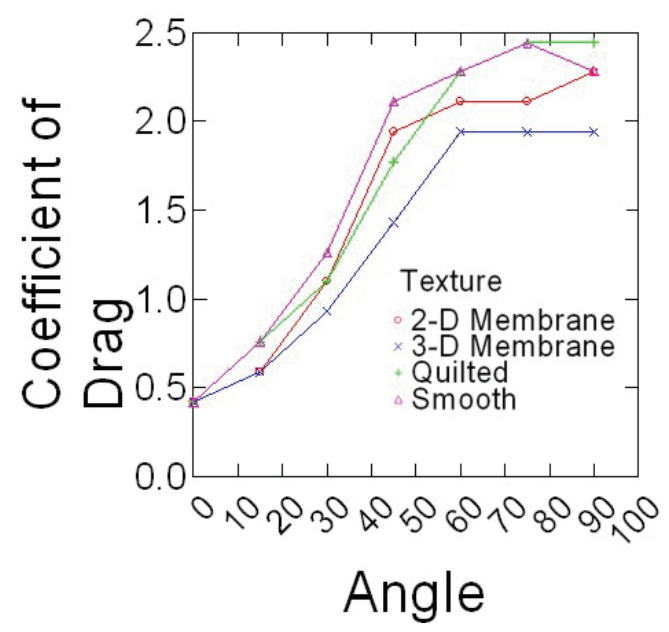

FIGURE 5. Drag coefficients of Charniodiscus spinosus epoxy models as a function of angle of attack relative to ambient flow and surface texture. Flow velocity $0.095 \mathrm{~m} / \mathrm{s}$.

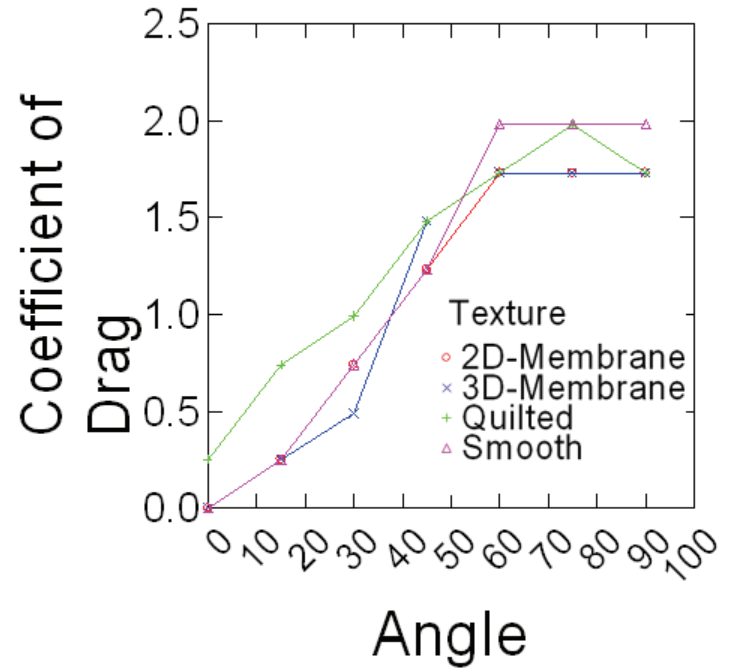

FIGURE 6. Drag coefficients of Charniodiscus procerus epoxy models as a function of angle of attack relative to ambient flow and surface texture. Flow velocity 0.095 $\mathrm{m} / \mathrm{s}$.

\section{RESULTS}

\section{Drag Coefficients}

Epoxy models did not bend in flow, and thus were ideally suited to isolate the effects that texture and orientation in flow had on overall drag. Changes in drag coefficient $\left(C_{d}\right)$ as a function of orientation among the different surface textures are shown in Figure 5 (C. spinosus) and Figure 6 (C. procerus), while combined results are shown in

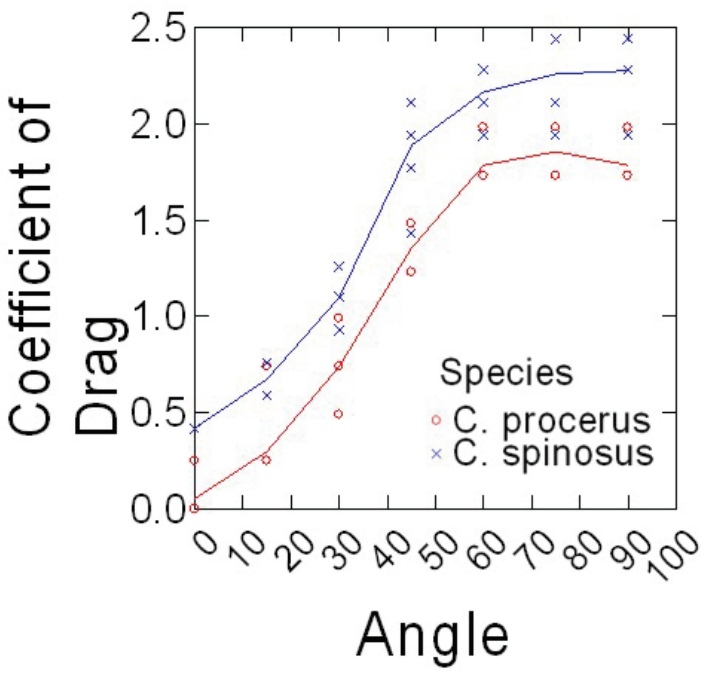

FIGURE 7. Drag coefficients as a function of angle of attack relative to ambient flow for Charniodiscus spinosus and C. procerus. Flow velocity $0.095 \mathrm{~m} / \mathrm{s}$. Fitted lines generated by locally weighted scatterplot smoothing (LOWESS). 


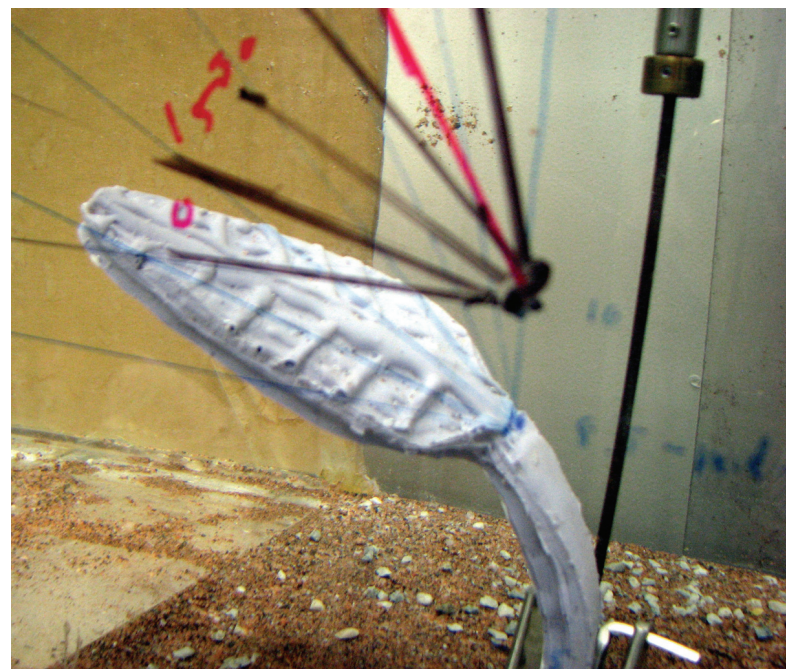

FIGURE 8. Silicon model of Charniodiscus spinosus bending in flow. Flow velocity $0.2 \mathrm{~m} / \mathrm{s}$, from right to left. Base of model mounted at bottom of tank.

Figure 7. All models were mounted as shown in Figure 4.

As would be expected, $C_{d}$ does vary with orientation; e.g., a flat plate has a much lower value relative to flow when it is parallel than when it is perpendicular to flow. On the other hand, this can be misleading. Drag can increase nonlinearly as a function of orientation because of changes in flow patterns; this in one reason airplanes stall.

For all models, drag is greatest at orientations $>60^{\circ}$ from horizontal and varies little within this range $\left(60^{\circ}-90^{\circ}\right)$. Below $60^{\circ}$, drag drops off rapidly, with the drag at $30^{\circ}$ being roughly half of that at $60^{\circ}$. In most cases and for both species, the lowest drag coefficients are associated with the 3-D models and the highest with the models with no surface structure suggesting that surface structures act as a drag reducing mechanism.

Most interesting is the comparison among species. Across all angles, and for nearly every texture, the coefficient of drag on C. procerus is less that of $C$. spinosus. Charniodiscus procerus is taller and thus should be further elevated out of the low-velocity benthic boundary layer and thus might experience higher velocities. The lower drag coefficient would lower total drag of this species.

\section{Material Properties}

Qualitative observations showed that, as velocity increased, the compliant models (agar and silicon), initially oriented erect and perpendicular to flow, bent to become more parallel to the flow direction (Figure 8). In order to examine the impact

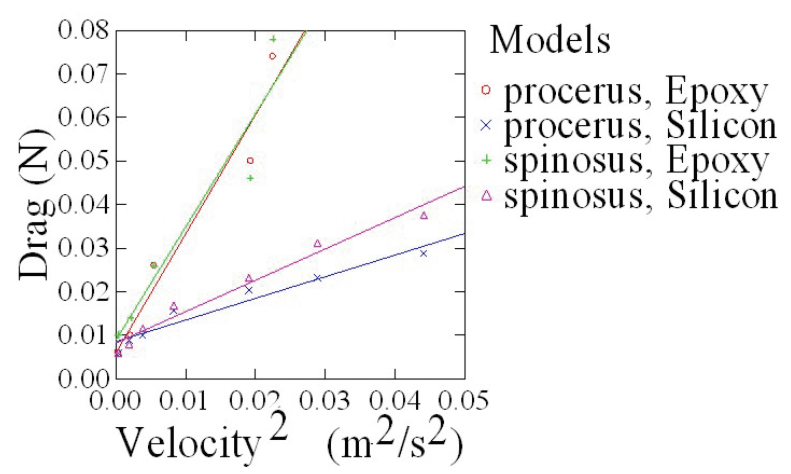

FIGURE 9. Drag on epoxy (stiff) and silicon (compliant) models as a function of velocity squared. Velocity squared is used since drag is linear with respect to velocity squared. Base of stem mounted near bottom of tank; stalk perpendicular to flow at zero velocity. Linear regression lines for the two species and materials shown.

of this change in orientation on the forces experienced by the fronds, in particular at the base, the drag forces experienced by both epoxy (rigid) and silicon (compliant) models were measured over a range of flow velocities. As demonstrated in Figure 9, which plots force in Newtons against velocity squared, silicon models of both species experience far less drag at higher velocities than comparable epoxy models due to their ability to reorient in flow.

Interestingly, the silicon models of $C$. procerus experience lower drag than those of $C$. spinosus. This difference becomes more pronounced as velocity increases thus perhaps explaining why $C$. procerus has a relatively smaller holdfast.

\section{Movements in Flow}

In addition to reorientation to become more parallel to flow, the flexible models, especially those made of agar, showed dynamic movements in the flow environment. Although some of these movements were probably due to turbulence within the tank itself, others were quite clearly related to the morphology of the frond and the resulting flow patterns (Figure 10).

Observed motions depended upon species and modeled surface structure, and orientation of model relative to flow. For $C$. spinosus, quilted models nearly parallel to flow showed the strongest motions (Figure 10). Motions observed included a vertical fluttering of the spire up and down, a transverse oscillation occurring lateral across the frond, and a sinusoidal wave along the length of the frond. 


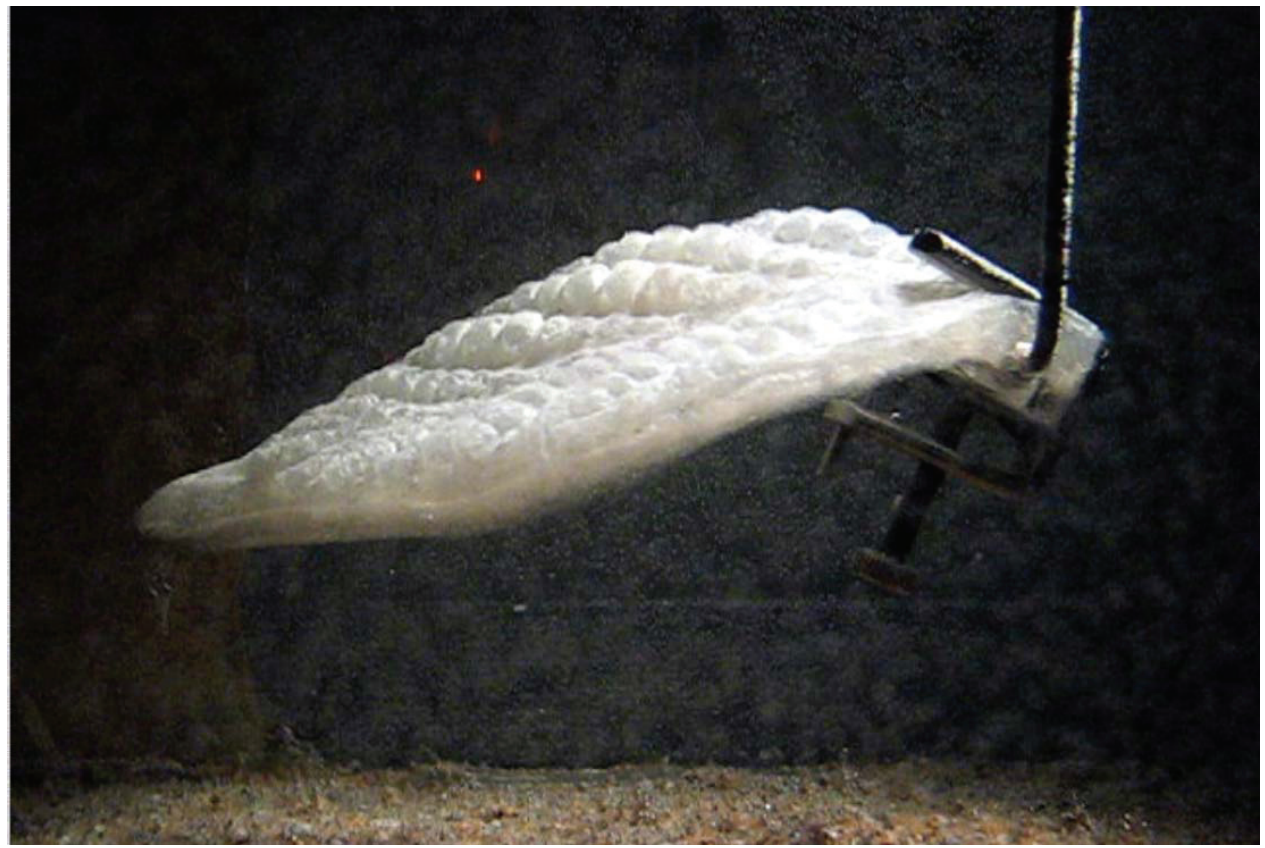

FIGURE 10. Video of an agar model of Charniodiscus spinosus with quilted surface showing overall movements in frond and movement of flow around and along surface of frond. Observed motions include vertical vibrations limited to the tip of the frond; motion laterally across the frond typically observed at the margins of the petalodium, and slow sinusoidal vibrations along the entire length of the frond. The dye streams show backflow along the surface of the frond, concentrated in the "canals" produced by the texture. Velocity is approximately $0.1 \mathrm{~m} / \mathrm{s}$. (See website for video.)

Particularly interesting was that compliant models of $C$. procerus, especially when mounted close to upright, exhibited pronounced periodic motions perpendicular to flow (Figure 11). The frond in this case appears to be acting as a "selfexcited oscillator," as described by Vogel (1981). In these systems, flow produces a lift force acting perpendicular to the net flow direction. This force then moves the object laterally. The object is then returned to the starting position by a restoring force.

In this case, it is possible that the bend in the C. procerus stalk exposes the two edges of the petalodium to different flow velocities, with the "upper" edge experiencing a greater velocity. This, in turn, will produce circulation around the frond and a resulting lateral force. When the two sides of the petalodium reach about the same distance from the substrate, the force declines, and the elasticity in the stem restores the frond to the starting position. This movement may have the effect, as seen in modern macroalgae, of stirring the water near the surface of the frond and thus increasing exchange rates.

\section{Surface Flow Movements}

One possible role of surface texture is to increase surface area of the frond over which exchange can take place. Dye streaklines were used to examine flow closest to the surface of the fronds and within the boundary layer (Vogel, 1981). In particular, attention was paid to whether ambient flow was captured (entrained) by the surface texture.

In the Smooth models, there was no evidence of flow entrainment. On the other hand, Membrane, Quilted, and 3-D models all entrained dye, resulting in flow being concentrated along the canals created by the surficial texture and dragged into secondary canals. For example, the quilted model of $C$. spinosus in Figure 10 shows entrainment of flow along the surface of the frond, including instances where dye flows moved upstream between the quilts.

Qualitative observations also suggest that different orientations produce changes in the type of vortices shed downstream of the fronds. At orientations of $60^{\circ}$ to $90^{\circ}$, vortices were shed in an alternating fashion known as von Karman trails, whereas from $0^{\circ}$ to $30^{\circ}$, vortices were shed in a 


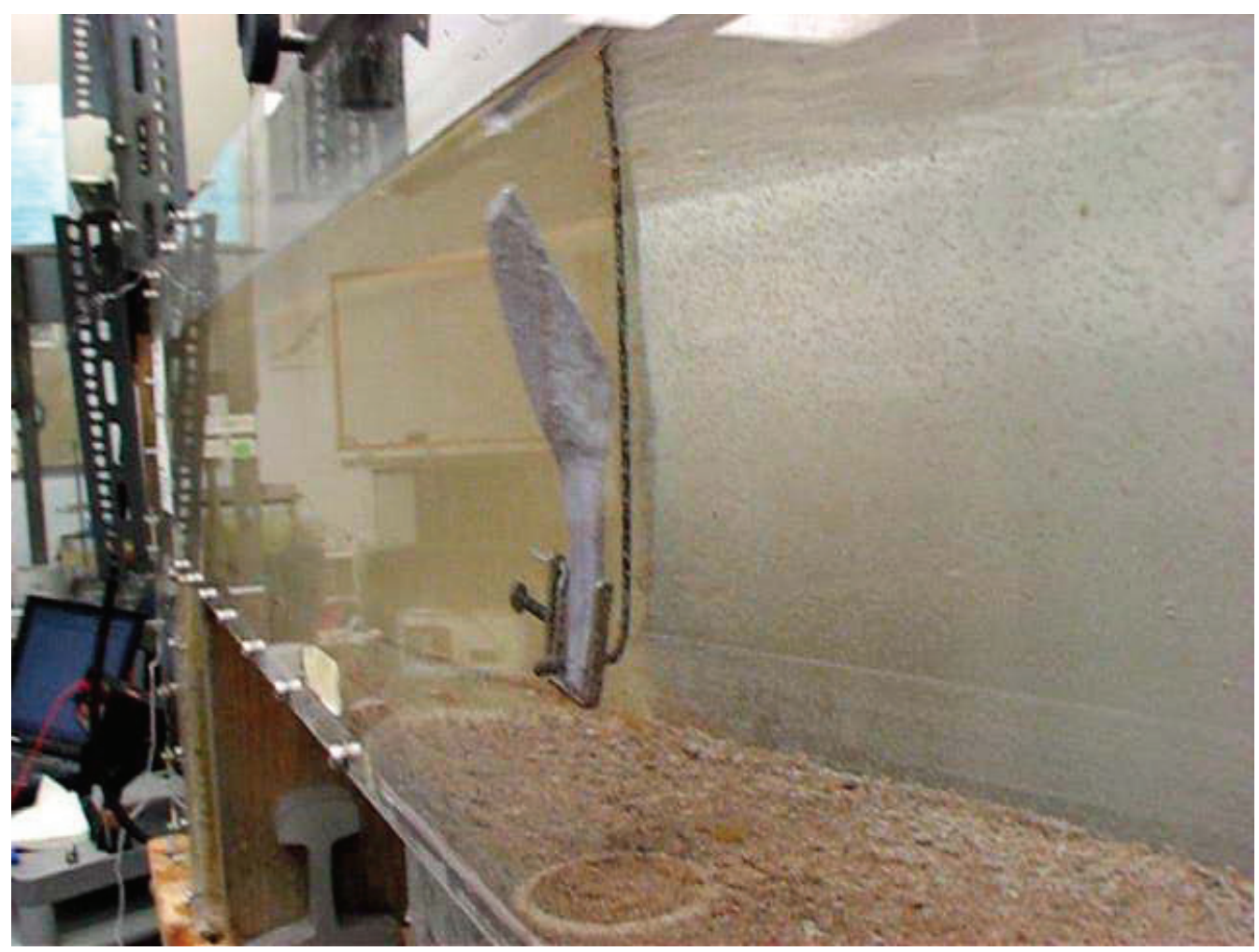

FIGURE 11. Video of periodic vibrations in silicon model of Charniodiscus procerus. Flow is away from the viewer, at approximately $0.10 \mathrm{~m} / \mathrm{s}$

spiral wake (Vogel, 1981). The alternative vortex shedding may also be responsible for the observed movements of the compliant models.

\section{DISCUSSION}

Numerous alternative reconstructions exist of the morphology and life mode of Ediacaran fronds (as reviewed in Laflamme and Narbonne, 2008a). There has also been no agreement on whether the frond material was stiff or compliant, or what orientation the fronds had to ambient flow. This study reveals how the architecture, tissue rigidity, and orientation in flow of Ediacaran fronds directly affect the interaction of the fronds with currents, and effectively constrains interpretations of their biology and ecology. In this section we return to the questions we asked at the beginning of the paper.

What is the effect of frond stiffness on its behavior in flow? The major impact of differences in compliance is the ability to reorient in flow. Silicon models visibly bent in flow, greatly reducing the drag they experienced compared to stiffer epoxy models. Furthermore, bending increased as flow velocity increased; the highly compliant agar models reoriented to flow even at very low veloci- ties. Should drag represent a major selective pressure effecting frond design, these results suggest that a completely rigid structure, i.e., one unable to reorient to reduce drag (Vogel, 1981), was an unlikely alternative.

How does orientation with respect to flow change drag and flow patterns? Based on the epoxy models, drag forces are highest and relatively constant when the fronds were oriented between $60^{\circ}$ and $90^{\circ}$ degrees relative to overall flow and dropped off markedly at lower angles. The change indicates that the ability to reorient to flow would drastically reduce strain on the frond structure at higher velocities, and effectively argues for a relatively compliant morphology for the frond petaloid.

What is the effect of frond three-dimensional morphology on flow interaction and forces? Alternative reconstructions of surface texture had measurable impacts on drag as well as observable differences in how they entrained flow. The highest drag was experienced by models lacking surface texture. For both species and most orientations, the preferred 3-D membrane model had the lowest drag. In terms of flow entrainment, all textured 
models showed entrainment to some extent, with the Quilted models showing the clearest patterns.

These results demonstrate that a solid-bodied frond with a textured surface can reduce drag and capture fluids. This ability would have significant implications for osmotrophic feeding strategies hypothesized for Ediacaran rangeomorphs (Sperling et al., 2007; Laflamme et al., 2009).

What is the significance of the morphologic differences between the two species of Charniodiscus? In particular, what is the potential significance of the bend in $\mathrm{C}$. procerus?

Flow-induced vibrations in the non-rigid models were unexpected. They have important implications for the understanding of how these organisms behaved in flow and may serve to explain key morphological differences between species.

C. procerus fossils have a long stem with a smaller petalodium and a distinct bend at the joint where the petalodium attaches to the stem. Most specimens of this species exhibit this bend, which supports this as a true feature of the organism (Laflamme et al., 2004). Charniodiscus procerus models reconstructed with this bend vibrate in a unique manner compared to $C$. spinosus models (and C. procerus models reconstructed without the bend). Bent fronds rhythmically vibrate perpendicular to flow, in a "waving" or inverted pendulum motion. This behavior may be produced by the pattern of vortex shedding produced by the asymmetry; i.e, these are self exciting oscillators that preferentially shed vortices in one direction (Vogel, 1981). Models without the bend do not produce this response; they behaved similar to $C$. spinosus models. Charniodiscus procerus model vibrations were most pronounced at $90^{\circ}$ (with silicon models), but occurred at all angles of orientation beyond $0^{\circ}$.

C. spinosus are shorter, broader, and have a characteristic spine that is an extension of the stalk beyond the tip of the petalodium. Although not as distinctive as the $C$. procerus vibration, $C$. spinosus models vibrated in some manner at all orientations beyond $0^{\circ}$ but were most pronounced in agar/carrageenan models at orientation of at $60^{\circ}$.

A long-standing question of how Ediacaran fronds may have survived in low flow environments in close packed communities may be in part resolved by the observed vibrations of the frond models. The vibrations observed here would have increased flow at the frond surface, perhaps in order to maximize adsorption at these low velocity regimes. Vibrations may have also reduced the "shadow effect" caused by growing in closely packed aggregates. By vibrating in flow, fronds are not excluded from fresh flows by upstream neighbors. Additionally, the differences in vibration strategies resulting from morphological differences between $C$. procerus and $C$. spinosus may have allowed them to maximize slightly different feeding strategies from different heights in the water column (Laflamme et al., 2004). It is also possible that these vibrations served, as they do in some algae, as an antifouling mechanism.

Like phototrophs, symbionts require sufficient gas exchange to enable the chemical reactions which they depend upon for energy. As discussed above, alga within the same species will adjust their morphology in low flow environments to a broad ruffled blade that encourage vibrations (Boller and Carrington, 2006; Stewart, 2006), since vibrations increase turbulent flow at the blade surface that will, in turn, increase gas exchange. Vibrations observed in models of Charniodiscus could have served a similar purpose of enhancing flow to allow the necessary gas/dissolved nutrient exchange to occur in these low velocity environments. Vibrations are not consistent with filter feeding organisms, which maintain a rigid posture and feed in the turbulent wake downstream of the structure (Levinton, 2001). The presence of vibrations in all compliant models lends strong support to the likelihood that Ediacaran fronds vibrated in flow, thus facilitating gas exchange.

\section{What is the possible range of forces exerted on the holdfast?}

Complete fronds (holdfast to tip) are rare except at the Mistaken Point locality (Laflamme et al., 2004; Gehling et al., 2005). It has been hypothesized that some specimens of the form genera Aspidella likely represent the basal rooting holdfast to Ediacaran fronds (Gehling et al., 2000). Aspidella has been difficult to interpret, with ascribed affinities ranging from fungal, through cnidarian polyps to bacterial colonies (Grazhdankin and Gerdes, 2007; Gehling et al., 2000; MacGabhann, 2007; and references therein). The overwhelming number of specimens are found lacking any morphological structures beyond a series of concentric rings, which prompted Grazhdankin and Gerdes (2007) to make the association with bacterial colonies (so called "fairy-rings"), however, several specimens have been found with prominent stemlike structures (Gehling et al., 2000) in which case the legitimacy of Aspidella as a rooting holdfast is difficult to refute. Further difficulties surrounding Aspidella is how to explain the absence of a stem and frond in most specimens. It has been sug- 
gested that when the fronds were subjected to high current velocities associated with storms or turbidites, the stems and petaloids were ripped from the holdfast, leaving only the circular disc behind. However, recent taphonomic studies have instead proposed that frond holdfasts were embedded within the microbial mat that formed the basis for Death Mask preservation (Gehling, 1999), thus preferentially preserving the holdfasts and creating a taphonomic bias with regards to Aspidella (Laflamme et al., 2011). The differential preservation of holdfasts would help explain the extensive temporal and geographic distribution of Aspidella when compared to all other Ediacaran organisms, in addition to explain the overwhelming dominance of Aspidella in certain environmental settings.

Our experiments shed further light on this issue. According to Vogel (2003), the tensile strength of an algal stipe is about $3 \mathrm{MPa}$, which is actually at the low end for biological materials. If we assume that fronds had similar physical properties, we can roughly estimate the velocities needed to tear the materials. At higher Reynolds numbers, drag coefficients are more-or-less constant over the range of possible velocities (Vogel, 1981). Using a $C_{d}$ value of 1.5 and a stem diameter of $0.01 \mathrm{~m}$, flow velocities greater than $8 \mathrm{~m} / \mathrm{s}$ would produce a stress in excess $3 \mathrm{MPa}$. This range of velocities is on order of those produced by a turbidity flow (Hsu et al., 2008), but far higher than that of typical deep water flows (Rhein, 1994). It should be pointed out that about the same forces would be acting on the attachment of the holdfast to the substrate, leading to the removal of the intact organism (Tarhan et al., 2010). These are very preliminary results and should be investigated in future studies.

\section{SUMMARY}

There have been rapid advances in our understanding of the paleontology of Ediacaran fronds, based on detailed studies of their preserved morphology and of the associated environments of deposition (Laflamme and Narbonne, 2008a). This research has made it possible to produce realistic reconstructions of the fronds that can be used in experimental studies of their functional morphology, in particular their interactions with flow.

The fluid biomechanics of two related species of frond, Charniodiscus spinosus and C. procerus from the Mistaken Point Formation of Newfoundland, Canada were modeled. We examined the interactions of flow with these forms as functions of their orientation to flow, the range of possible material properties and alternative surface reconstructions, as well as differences between the species. Our experiments included measurements of the drag forces and associated coefficients of drag, as well qualitative observations of flow patterns.

Our results indicate that the highest drag forces occur when fronds are facing directly into flow. The ability to passively reorient to become more parallel to flow markedly reduces these forces and would correspondingly reduce the stresses placed on the holdfast and stem. This effect would only be achieved if the fronds were at least somewhat compliant.

We also observed that compliant models exhibit a variety of vibrations in flow. Especially noteworthy is that $C$. procerus might behave as a self-exciting oscillator, producing a periodic backand-forth motion in flow. These vibrations, which would stir water at the surface of the fronds, could serve to reduce the thickness of the boundary layer and increase exchange rate.

Surface texture on the fronds both reduced drag and acted to entrain flow. These results, as well as the observed vibrations, are consistent with the reconstruction of these forms as osmotrophs, as suggested by Sperling et al. (2007) and Laflamme et al. (2009).

Our results also have direct implications for the understanding of the forces that might uproot these forms or separate them from their holdfasts. In this case, the key variables that remain unknown are the material properties of the fronds and anchoring biomats, as well as the maximum velocities of flow encountered.

Finally, these preliminary studies on the interaction of flow in and around Ediacaran organisms showcases the benefits of experimental modeling applied to enigmatic fossil constructions. Such experiments can set realistic boundaries on the likely construction, original material consistency, and hypothesized passive reorientation behavior of these long lost critters. Prior to widespread macropredation, it has been suggested that filter-feeding and osmotrophy were the dominant trophic strategies, and that a diverse expansion in predation (and other trophic strategies) ushered in the Cambrian explosion of metazoan ecosystem dominance (Erwin et al., 2011). Therefore, constraining the efficiency of Ediacaran fronds in response to flow represents an essential step to understanding the earliest communities of macroscopic life. 


\section{ACKNOWLEDGMENTS}

This material is based upon work supported by the National Science Foundation under Grant EAR- 0921771 to Plotnick. L. Perper assisted Plotnick in the lab. We are indebted to G. Narbonne of Queens University for making specimens available for this study and sharing his knowledge of the Ediacaran fronds. Singer would like to extend a special thanks to M. LaBarbera of University of Chicago, M. Denny of Stanford University, E. Carrington of University of Washington Friday Harbor Laboratory, and J. Gosline of University of British Columbia for inspiration and illuminating the world of Biomechanics. Singer is also grateful for funding from the Wainwright Fund, which enabled her to study at Friday Harbor Labs and attend the Biomechanics course. Laflamme acknowledges the generous support of the National Sciences and Engineering Council of Canada (NSERC), the Bateman Postdoctoral Fellowship in the Department of Geology and Geophysics at Yale University, and the Smithsonian Postdoctoral Fellowship Program. S. Xiao and an anonymous reviewer are thanked for their comments.

\section{REFERENCES}

Baumiller, T.K. 1990. Physical modeling of the batocrinid anal tube - functional analysis and multiple hypothesis-testing. Lethaia, 23:399-408.

Baumiller, T.K. and Plotnick, R.E. 1989. Rotational stability in stalked crinoids and the function of wing plates in Pterotocrinus depressus. Lethaia, 22:317-326.

Boller, M.L. and Carrington. E. 2006. The hydrodynamic effects of shape and size change during reconfiguration of a flexible macroalga. Journal of Experimental Biology, 209:1894-1903.

Brasier, M.D. and Antcliffe, J. 2009. Evolutionary relationships within the Avalonian Ediacara biota: new insights from laser analysis. Journal of the Geological Society, London, 166:363-384

Buss, L.W. and Seilacher, A. 1994. The Phylum Vendobionta: A sister group of the Eumetazoa? Paleobiology, 20:1-4.

Clapham, M.E. and Narbonne, G.M. 2002. Ediacaran epifaunal tiering. Geology, 30:627-630.

Darroch, S., Laflamme, M., Schiffbauer, J.D. and Briggs, D.E.G. 2012. Experimental Formation of a Microbial Death Mask. Palaios, 27: 293-303.

Denny, M. and Gaylord, B. 2002. The mechanics of wave-swept algae. Journal of Experimental Biology, 205:1355-1362.

Dzik, J. 2003. Anatomical information content in the Ediacaran fossils and their possible zoological affinities. Integrative and Comparative Biology, 43:114-126.
Erwin, D.H., Laflamme, M., Tweedt, S.M., Sperling, E.A., Pisani, D., and Peterson, K.J. 2011. The Cambrian conundrum: early divergence and later ecological success in the early history of animals. Science, 334:1091-1097.

Ford, T.D. 1958. Precambrian fossils from Charnwood Forest. Yorkshire Geological Society Proceedings, 31:211-217.

Gaylord, B., Hale, B.B., and Denny, M.W. 2001. Consequences of transient fluid forces for compliant benthic organisms. Journal of Experimental Biology, 204:1347-1360.

Gehling, J.G. 1991. The case for Ediacaran roots to the metazoan tree. Geological Society of India Memoir, 20:181-224.

Gehling, J.G. 1999. Microbial mats in terminal Proterozoic siliciclastics: Ediacaran death masks. Palaios, 14:40-57.

Gehling, J.G., Narbonne, G.M., and Anderson, M.A. 2000. The first named Ediacara body fossil, Aspidella terranovica. Palaeontology, 43:427-456.

Gehling, J.G., Droser, M.L., Jensen, S.R., and Runnegar, B.N. 2005. Ediacara organisms: relating form to function, p. 43-66. In Briggs, D.E.G. (ed.), Evolving Form and Function: Fossils and Development. Peabody Museum of Natural History, Yale University, New Haven, Connecticut.

Glaessner, M.F. 1984. The Dawn of Animal Life; A biohistorical study. Cambridge Earth Science Series. Cambridge University Press, New York.

Grazhdankin, D. and Gerdes, G. 2007. Ediacaran microbial colonies. Lethaia, 40:201-210.

Hsu, S., Kuo, J., Lo, C., Tsai, C., Doo, W., Ku, C., and Sibuet, J. 2008. Turbidity currents, submarine landslides and the 2006 Pingtung earthquake off SW Taiwan. Terrestrial, Atmospheric and Oceanic Sciences, 19:767-772.

Hurd, C.L. and Pilditch, C.A. 2011. Flow-induced morphological variations affect diffusion boundary-layer thickness of Macrocystis pyrifera (Heterokontophyta, Laminariales). Journal of Phycology, 47: 341-351.

Koehl, M.A.R. and Alberte, R.S. 1988. Flow, flapping, and photosynthesis of Nereocystis luetkeana - a functional comparison of undulate and flat blade morphologies. Marine Biology, 99:435-444.

Koehl, M.A.R., Silk, W.K., Liang, H., and Mahadevan, L. 2008. How kelp produce blade shapes suited to different flow regimes: a new wrinkle. Integrative and Comparative Biology, 48:834-851.

Laflamme, M. and Narbonne, G.M. 2008a. Ediacaran fronds. Palaeogeography Palaeoclimatology Palaeoecology, 258:162-179.

Laflamme, M. and Narbonne, G.M. 2008b. Competition in a Precambrian world: palaeoecology and functional biology of Ediacaran fronds. Geology Today, 24:182-187. 
Laflamme, M., Narbonne, G.M., and Anderson, M.M. 2004. Morphometric analysis of the Ediacaran frond Charniodiscus from the Mistaken Point Formation, Newfoundland. Journal of Paleontology, 78:827-837.

Laflamme, M., Narbonne, G.M., Greentree, C. and Anderson, M.M. 2007. Morphology and taphonomy of the Ediacaran frond: Charnia from the Avalon Peninsula of Newfoundland, p. 237-257. In P. VickersRich and P. Komarower (eds.), The Rise and Fall of the Ediacaran Biota. Special Publications, 286. Geological Society, London.

Laflamme, M., Xiao, S.H., and Kowaleski, M. 2009. Osmotrophy in modular Ediacara organisms. Proceedings of the National Academy of Sciences of the United States of America, 1060:14438-14443.

Laflamme, M., Schiffbauer, J.D., Narbonne, G.M., and Briggs, D.E.G. 2011. Microbial biofilms and the preservation of the Ediacara biota. Lethaia, 44:203-213.

Levinton, J. S. 2001. Marine Biology: Function, Biodiversity, Ecology. Oxford University Press, New York.

Lynch, M. 1999. The age and relationships of the major animal phyla. Evolution, 53:319-325.

MacGabhann, B.A. 2007. Discoidal fossils of the Ediacaran biota: a review of current understanding. Geological Society of London, Special Publications, 286:297-313.

Narbonne, G.M. 2005. The Ediacara Biota: Neoproterozoic origin of animals and their ecosystems. Annual Review of Earth and Planetary Sciences, 33:421442.

Narbonne, G.M., Laflamme, M., Greentree, C., and Trusler, P. 2009: Reconstructing a lost world: Ediacaran rangeomorphs from Spaniard's Bay, Newfoundland. Journal of Paleontology, 83:503-523.

Peterson, K.J., McPeek, M.A., and Evans, D.A.D. 2005. Tempo and mode of early animal evolution: Inferences from rocks, Hox, and molecular clocks. Paleobiology, 31(supplement):36-55.

Raven, P.H., Evert, R.F., and Eichhorn, S.E. 2005. Biology of Plants. Macmillan, New York.

Retallack, G. J. 1994. Were the Ediacaran fossils lichens? Paleobiology, 20:523-544.

Rhein, M. 1994. The Deep Western Boundary Current tracers and velocities. Deep-Sea Research Part IOceanographic Research Papers, 41:263-281.

Riisgard, H.U. and Larsen, P.S. 2010. Particle capture mechanisms in suspension-feeding invertebrates. Marine Ecology-Progress Series, 418:255-293.

Schopf, K.M. and Baumiller, T.K. 1998. A biomechanical approach to Ediacaran hypotheses: how to weed the Garden of Ediacara. Lethaia, 31:89-97.
Seilacher, A. 1989. Vendozoa - organismic construction in the Proterozoic biosphere. Lethaia, 22:229-239.

Seilacher, A. 1992. Vendobionta and Psammocorallia lost constructions of Precambrian evolution. Journal of the Geological Society, 149:607-613.

Seilacher, A. 1999. Biomat-related lifestyles in the Precambrian. Palaios, 14:86-93.

Sperling, E.A., Peterson, K.J., and Laflamme, M. 2011. Rangeomorphs, Thectardis (Porifera?) and dissolved organic carbon in the Ediacaran ocean. Geobiology, 9:24-33.

Sperling, E.A., Pisani, D., and Peterson, K.J. 2007. Poriferan paraphyly and its implications for Precambrian palaeobiology. Geological Society of London, Special Publications, 286:355-368.

Sponaugle, S. and Labarbera, M. 1991. Drag-induced deformation - a functional feeding strategy in two species of Gorgonians. Journal of Experimental Marine Biology and Ecology, 148:121-134.

Stewart, H.L. 2006. Morphological variation and phenotypic plasticity of buoyancy in the macroalga Turbinaria ornata across a barrier reef. Marine Biology, 149:721-730

Tarhan, L.G., Droser, M.L., and Gehling, J.G. 2010. Taphonomic controls on Ediacaran diversity: uncovering the holdfast origin of morphologically variable enigmatic structures. Palaios, 25:823-830.

Waggoner, B. 2003. The Ediacaran biotas in space and time. Integrative and Comparative Biology, 43:104113.

Wainwright, S.A. and Dillon, J.R. 1969. On the orientation of sea fans (Genus Gorgonia). Biological Bulletin, 136:130-139.

Wood, D.A., Dalrymple, R.W., Narbonne, G.M., Gehling, J.G., and Clapham, M.E. 2003. Paleoenvironmental analysis of the late Neoproterozoic Mistaken Point and Trepassey formations, southeastern Newfoundland. Canadian Journal of Earth Sciences, 40:13751391.

Vogel, S. 1981. Life in Moving Fluids. Princeton University Press, Princeton, New Jersey.

Vogel, S. 2003. Comparative Biomechanics: Life's Physical World. Princeton University Press, Princeton, New Jersey.

Vogel, S., and Labarbera, M. 1978. Simple flow tanks for research and teaching. Bioscience, 28(10):638-643.

Xiao, S.H. and Laflamme, M. 2009. On the eve of animal radiation: phylogeny, ecology and evolution of the Ediacara biota. Trends in Ecology \& Evolution, 24:3140. 